\title{
Body Volume and Fat-Free Mass Determinations by Acoustic Plethysmography ${ }^{1}$
}

\author{
HWAI-PING SHENG, ANNE L. ADOLPH, E. O'BRIAN SMITH, AND CUTBERTO GARZA \\ USDA/ARS Children's Nutrition Research Center, Department of Pediatrics and Department of Physiology and \\ Molecular Biophysics, Baylor College of Medicine, and Texas Children's Hospital Houston, Texas 77030
}

\begin{abstract}
An acoustic plethysmograph designed to measure body volumes of infants is described. This method uses the principle of the Helmholtz resonator in which the resonant frequency of a chamber is inversely proportional to the square root of the volume of air inside the chamber. After an object is placed inside the chamber, the change in resonant frequency is used to measure the volume of the object. The coefficient of variation of repeated measures of body volumes of 13 miniature piglets ( 5 to 18 days old, body weights 1253 to $2631 \mathrm{~g}$ ) ranged from 0.3 to $3.2 \%$. Body volumes measured by the acoustic method agree closely with those calculated from carcass analysis in which body volume is the sum of the volumes of total body water, fat, protein, and minerals. Fat-free mass computed from densitometry using a four-compartment model and body volume measurements from the acoustic method agrees with fat-free mass obtained from carcass analysis. The mean difference between methods was not significant: $1 \mathrm{ml}$ for body volume and $3 \mathrm{~g}$ for fat-free mass. The limits of agreement between methods was $\pm 75 \mathrm{ml}$ for body volume and $\pm 214 \mathrm{~g}$ for fat-free mass. Our results indicate that the acoustic method can measure a change in body volume of $75 \mathrm{ml}$ and a change in fat-free mass of $214 \mathrm{~g}$ in a 2000 g infant. (Pediatr Res 24: 85-89, 1988)
\end{abstract}

Assessments of energy metabolism and requirements of infants have been impeded by the paucity of acceptable methods to determine body composition. Of the various techniques that have been explored, those based on densitometry (1) have the most appeal because they are noninvasive and can be used repeatedly over short periods.

The determination of body density requires the measurement of body mass and volume. Although accurate measures of body mass can be obtained, no satisfactory method exists for the measurement of the body volume of infants. Underwater weighing $(2,3)$ and water displacement $(4)$ methods are considered to be reliable for the estimation of body volume of adults, however, they are not feasible for measurements in infants because they require submersion of the subject. Therefore, methods, such as photogrammetry (5), air displacement (6), helium displacement

Received October 9, 1987; accepted March 3, 1988

Correspondence and reprint requests Hwai-Ping Sheng, Ph.D., Children's Nutrition Research Center, 6608 Fannin, Suite 601, Houston, TX 77030.

Publication of the USDA/ARS Children's Nutrition Research Center, Department of Pediatrics, Baylor College of Medicine and Texas Children's Hospital. Supported in part with federal funds from the United States Department of Agriculture, Agricultural Research Service under Cooperative Agreement 58$7 \mathrm{MN} 1-6-100$.

${ }^{1}$ The contents of this publication do not necessarily reflect the views of policies of the United States Department of Agriculture, nor does mention of trade names, commercial products, or organizations imply endorsement by the United States government.
(7), pressure differential $(8,9)$, and a combination of water and air displacement $(10,11)$ have been explored. None of those methods is without technical difficulties: e.g. changes in chamber pressures due to alterations in chamber temperature and respiratory gas exchange and evaporative water losses from the subjects.

In collaboration with colleagues from the University of Houston, we developed an acoustic plethysmograph, based on the Helmholtz resonator principle $(12,13)$. A detailed discussion of the theory and construction of an early prototype resonating chamber has been published $(12,13)$. Preliminary validation of this method based on measurements of inanimate objects and anesthetized infant miniature pigs demonstrated the potential usefulness of this method for body volume measurements in infants $(12,13)$.

We designed the present experiment to assess the validity of the acoustic plethysmograph to measure body volumes and to estimate the fat-free mass of anesthetized infant miniature pigs. Values of body volume obtained by the acoustic method were compared with estimates of body volume calculated from the chemical analysis of the whole carcass. Values of fat-free mass estimated from body density were compared with those obtained from carcass analysis.

\section{METHODS}

Experimental design. Thirteen infant miniature pigs of the Pitman-Moore/Hanford strain were used (Bastrop Farms, Bastrop, TX). The animals ranged in age from 5 to 18 days and in body weight from 1253 to $2631 \mathrm{~g}$. The piglets were anesthetized with a combination of ketamine $(20 \mathrm{mg} / \mathrm{kg})$, administered intramuscularly, and pentobarbital $\mathrm{Na}(10 \mathrm{mg} / \mathrm{kg})$, administered intraperitoneally, after which they were shaved and weighed. Body weights were measured within $\pm 0.5 \mathrm{~g}$. Body volumes were measured with the acoustic plethysmograph. After the measurements, the piglets were killed with an overdose of pentobarbital $\mathrm{Na}$, and their chemical composition was determined by carcass analysis.

Body volume measurement using acoustic plethysmography. Measurements of body volume with the acoustic plethysmograph are based on the principle of the Helmholtz resonator $(12,13)$. The Helmholtz resonator consists of a chamber with a volume of air coupled to a source of sound waves (a speaker). The frequency of the generated sound waves is varied over a small range until a maximum sound level, which corresponds to the resonant frequency, is reached inside the chamber. The resonant frequency is inversely proportional to the square root of the volume of air inside the chamber. When an object is placed inside the chamber, the volume of air is altered and a change is produced in the resonant frequency.

The prototype instrument consists of a rectangular acrylic box with a hinged front to provide access into the chamber. A speaker, which is the source of sound waves, is mounted directly above a circular opening on the chamber's top surface. The speaker is 
driven by a sine-wave generator and its frequency is controlled by computer. The sound level in the chamber is detected by a microphone whose signal is amplified, filtered, and monitored by computer. The sound level in the chamber is less than 65 decibels. The frequency of the loudspeaker's signal is varied in response to a searching program designed to identify the resonant frequency. The resonant frequency of the system ranged between 100 and $120 \mathrm{~Hz}$. The sound level at this frequency is barely audible and is innocuous to the infant. The resonating chamber and its external environment are maintained at a fixed temperature by placing the chamber, speaker, and two space heaters in a larger enveloping acrylic chamber. A diagrammatic representation is shown in Figure 1.

The resonant frequencies produced when blocks of known volumes were placed in the chamber were used to construct a calibration curve. The volumes ranged from 1000 to $3000 \mathrm{ml}$. Body volumes of the anesthetized piglets were computed from the calibration curve using the measured resonant frequencies for the individual piglets. All measurements for the calibration curve and piglets were done at $35^{\circ} \mathrm{C}$, a temperature appropriate for piglets at that age. Ten 1-min measurements were made on each piglet. An average of the measurements was used to estimate body volume.

Body volumes computed from chemical composition. The total amounts of body water, fat, protein, and minerals of the carcass were determined using established laboratory procedures $(14$, 15). Total body water was calculated from the difference between wet and dried carcass weights. The entire dried carcass was homogenized to a fine powder of which a portion was extracted with diethyl ether. The fat content was calculated as the difference between the weights of the dried and fat-free dried samples. The nitrogen content of the fat-free dried samples was determined by the micro-Kjeldahl method. Protein was calculated by multiplying the amount of nitrogen by 6.25 . Known weights of homogenized dried tissues were ashed to a constant weight in a muffle furnace at $500^{\circ} \mathrm{C}$. The amount of body minerals was calculated by multiplying body ash by a factor of 1.035 (1). All samples were analyzed in duplicates.

Body volume (V) was calculated as the sum of the volumes of the four chemical compartments: total body water (w), total body fat $(f)$, total body protein $(p)$, and total body minerals $(m)$. The volume of each was calculated from its weight (W) divided by its density (D). The following density values were used: 0.9937 (1), 0.914 (16), 1.34 (1), and 3.038 (1) for water, fat, protein and minerals, respectively.

$$
\mathrm{V}=\frac{\mathrm{W}(\mathrm{w})}{\mathrm{D}(\mathrm{w})}+\frac{\mathrm{W}(\mathrm{f})}{\mathrm{D}(\mathrm{f})}+\frac{\mathrm{W}(\mathrm{p})}{\mathrm{D}(\mathrm{p})}+\frac{\mathrm{W}(\mathrm{m})}{\mathrm{D}(\mathrm{m})}
$$

Calculation of fat-free mass from densitometric approach. Body fat was calculated by the densitometric method in which the body was divided into water, fat, protein, and minerals (1). The equations used assume that the sum of the weights and the sum of the volumes of the four compartments are equal to the total body weight and the total body volume, respectively.

$$
\mathrm{W}=\mathrm{W}(\mathrm{w})+\mathrm{W}(\mathrm{f})+\mathrm{W}(\mathrm{p})+\mathrm{W}(\mathrm{m})
$$

Equation 3 was derived from equations 1 and 2 when the density values of 0.9937 (1), 0.914 (16), 1.34 (1), and 3.038 (1) were used for water, fat, protein, and minerals, respectively.

$$
\mathrm{W}(\mathrm{f})=2.875 \mathrm{~V}-2.146 \mathrm{~W}-0.748 \mathrm{~W}(\mathrm{w})+1.199 \mathrm{~W}(\mathrm{~m})
$$

Total body fat can be calculated when the following values are known: body weight, body volume, total body water, and mineral weight. Body volume was measured by the acoustic method, total body water, and minerals were obtained from carcass analysis of each animal. The difference between total body weight and total body fat (fat mass) is the fat-free mass of the piglets.

Calculation of fat-free mass from carcass analysis. Values of fat-free mass were obtained from the difference between body weight and total body fat which was extracted with ether.

Calculation of body density. The body density of each piglet was calculated from its body mass divided by its body volume. Two body density values were calculated for each piglet; the first from body volume measurements obtained from the acoustic method and the second from body volume values computed from the chemical composition of the carcass.

Data analysis. We tested the reproducibility of the acoustic method by calculating the coefficient of variation of repeated measures of the volumes of inanimate objects and the body volumes of anesthetized miniature pigs. The agreement between body volumes measured by the acoustic method and those computed from the chemical analysis was assessed by a pair-wise comparison which showed the relative bias (mean difference) and the limits of agreement (mean difference $\pm 2 \mathrm{SD}$ of the differences) between the two methods. The differences between the two methods were plotted against the mean body volumes obtained from the two methods (17). Regression analysis was used to test for any significant relationship between the differences and the mean body volumes. The difference in body volumes between the two methods was tested for significance

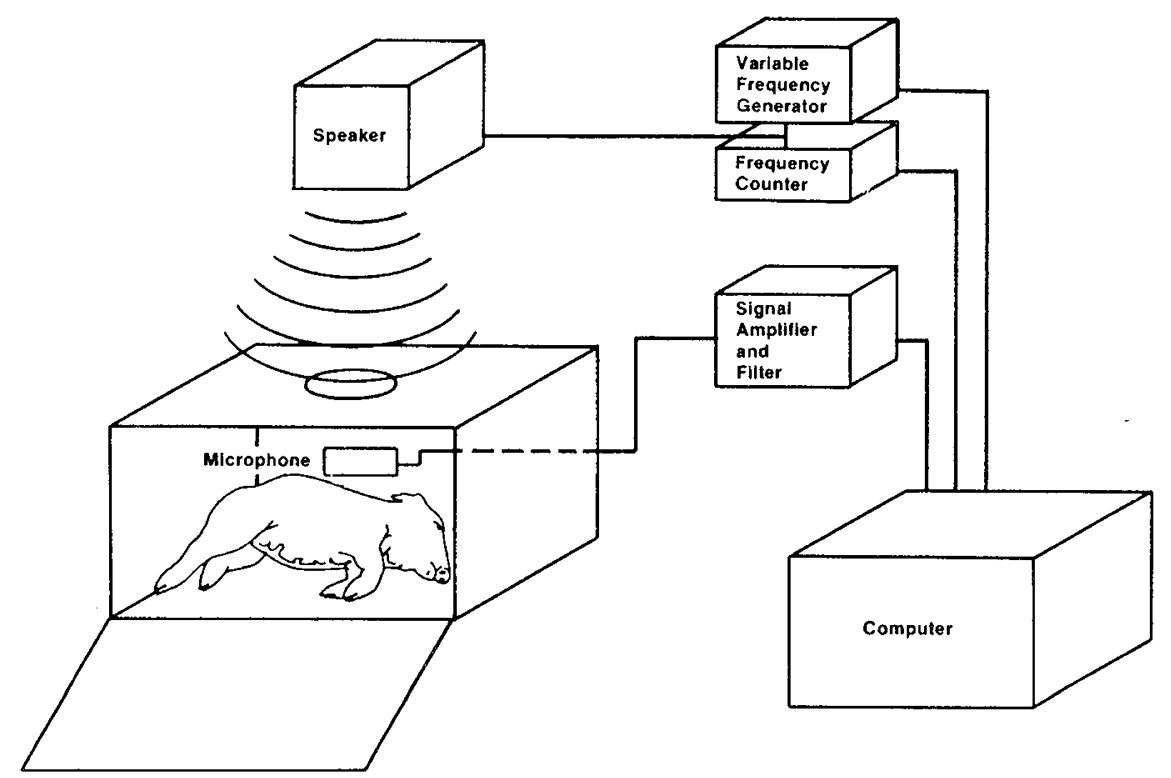

Fig. 1. Schematic representation of the acoustic plethysmograph for body volume measurements. The system is computer controlled. 
using a paired $t$ test $(17,18)$. A similar approach was used to assess the agreement between fat-free mass estimated by densitometry and that obtained from carcass analysis.

\section{RESULTS}

A linear relationship was observed between the resonant frequencies and the known volumes of solid blocks used to calibrate the chamber. This frequency-volume calibration curve was displaced by $0.2 \mathrm{~Hz}$ with every $1^{\circ} \mathrm{C}$ change in temperature. Therefore, all measurements were performed at $35^{\circ} \mathrm{C}$. The coefficient of variation of repeated measures of body volumes of the anesthetized minipigs ranged from 0.3 to $3.2 \%$. The higher values resulted from movements when the minipigs were lightly anesthetized.

Results of the acoustic measurements and chemical analysis are shown in Table 1. There were no significant differences when body volumes and densities obtained with the acoustic method were compared with those from chemical analysis (paired $t$ test, $p>0.9$ ). The difference between the two methods was less than $2.9 \%$, with a mean of $-0.02 \% \pm 1.72$.

The agreement between body volume measured by the acoustic method (Y) and that obtained from chemical analysis (X) was shown by the regression equation: $\mathrm{Y}=-8.4 \pm 1.0 \mathrm{X}$ (SEE $=38.9, r=0.995$ ) (Fig. 2). The intercept, $-8.4 \mathrm{ml}$, was not different from zero $(p>0.9)$. A plot of the differences of the volumes obtained from both methods against the mean volume is shown in Figure 3. The differences were determined to be distributed normally. The mean difference between methods of $-1 \mathrm{ml} \pm 37$ was not statistically significant $(p>0.9)$. The slope of the line was not significantly different from zero. The difference between the volumes measured by the two methods was not correlated with the absolute volume. Because the differences are normally distributed, $95 \%$ of the differences will lie between $+74 \mathrm{ml}$ and $-76 \mathrm{ml}$ which are defined as the upper and lower limits of agreement (mean difference \pm 2 SD of the differences).

Fat-free mass calculated by the densitometric method was in agreement with the value obtained by carcass analysis (Fig. 4). The slope (1.0) and intercept $(-1 \mathrm{~g})$ of the regression line are not significantly different from the line of identity $(p>0.9)$.

Normal distribution was determined for the differences of the fat-free mass obtained from both methods (Fig. 5). The mean difference between methods was $3 \mathrm{~g} \pm 107$ and was not statistically significant $(p>0.9)$. The difference between the fat-free mass obtained by the two methods was not correlated with the absolute fat-free mass. As the differences are normally distributed, $95 \%$ of the differences will be between +217 and $-211 \mathrm{~g}$.

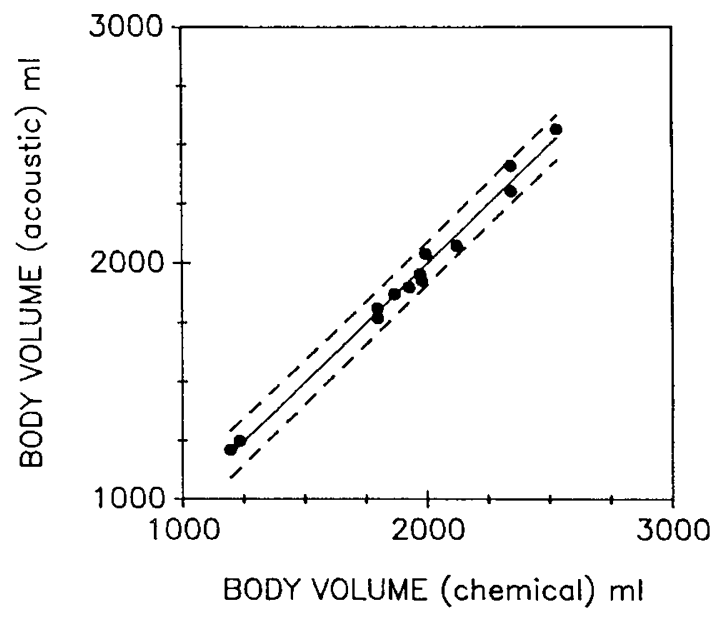

Fig. 2. Relationship between body volume measured by acoustic method $(\mathrm{Y})$ and body volume computed from carcass analysis $(\mathrm{X})$. The solid line represents the data fitted to the equation $\mathrm{Y}=-8.4 \pm 1.0 \mathrm{X}(r$ $=0.995)$. The SE of estimate of the regression line is $38.9 \mathrm{ml}$. The dashed line represents the $95 \%$ prediction interval.

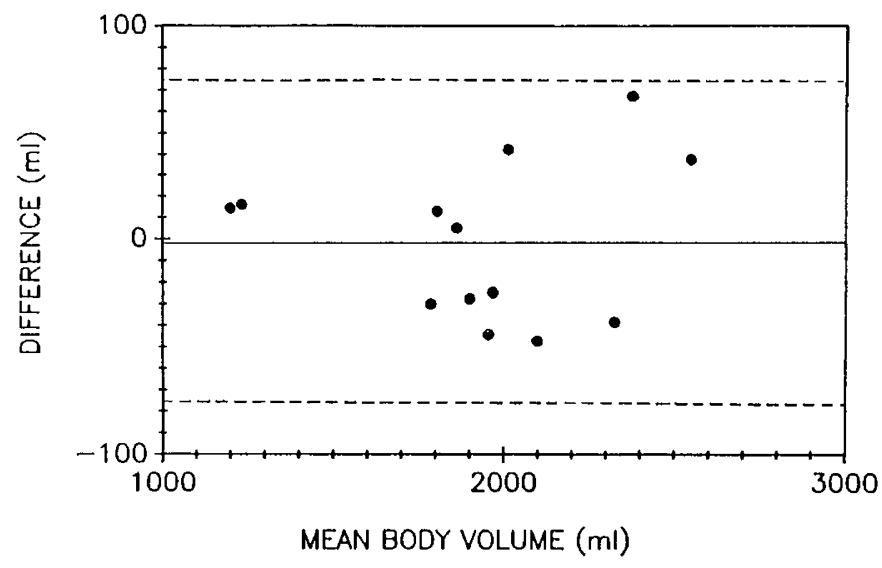

Fig. 3. Differences in body volume between the two methods (acoustic and chemical) are plotted against mean body volumes from the two methods. The solid line represents the mean difference and the dashed lines represent the upper and lower limits of agreement (mean difference \pm 2 SD of the differences) between the two methods.

Table 1. Body volume, body density, and fat-free mass from acoustic plethysmograph and chemical analysis

\begin{tabular}{|c|c|c|c|c|c|c|c|c|}
\hline \multirow[b]{2}{*}{ Pig } & \multirow[b]{2}{*}{$\begin{array}{c}\text { Mass } \\
(\mathrm{g})\end{array}$} & \multicolumn{3}{|c|}{ Body volume $(\mathrm{ml})$} & \multicolumn{2}{|c|}{ Body density (g/ml) } & \multicolumn{2}{|c|}{ Fat-free mass (g) } \\
\hline & & Acoustic & Chemical & $\begin{array}{c}\% \\
\text { Difference }\end{array}$ & Acoustic & Chemical & Densitometry & Chemical \\
\hline 1 & 1253 & 1209 & 1195 & +1.2 & 1.037 & 1.049 & 1095 & 1136 \\
\hline 2 & 1292 & 1248 & 1233 & +1.2 & 1.035 & 1.048 & 1125 & 1167 \\
\hline 3 & 1866 & 1810 & 1796 & +0.8 & 1.031 & 1.039 & 1628 & 1668 \\
\hline 4 & 1890 & 1769 & 1799 & -1.6 & 1.068 & 1.051 & 1764 & 1678 \\
\hline 5 & 1930 & 1871 & 1867 & +0.2 & 1.032 & 1.034 & 1596 & 1609 \\
\hline 6 & 2011 & 1900 & 1927 & -1.4 & 1.058 & 1.044 & 1851 & 1773 \\
\hline 7 & 2060 & 1955 & 1979 & -1.2 & 1.054 & 1.041 & 1977 & 1909 \\
\hline 8 & 2066 & 1929 & 1973 & -2.2 & 1.071 & 1.047 & 1947 & 1821 \\
\hline 9 & 2083 & 2039 & 1995 & +2.2 & 1.022 & 1.044 & 1728 & 1855 \\
\hline 10 & 2231 & 2074 & 2122 & -2.3 & 1.076 & 1.051 & 2123 & 1984 \\
\hline 11 & 2444 & 2409 & 2342 & +2.9 & 1.015 & 1.044 & 1956 & 2151 \\
\hline 12 & 2467 & 2304 & 2343 & -1.7 & 1.071 & 1.053 & 2416 & 2305 \\
\hline 13 & 2631 & 2567 & 2527 & +1.6 & 1.025 & 1.041 & 2234 & 2347 \\
\hline Mean \pm & & 1930 & 1931 & -0.02 & 1.046 & 1.045 & 1803 & 1800 \\
\hline $\mathrm{SD}$ & & 376 & 373 & 1.72 & 0.020 & 0.005 & 370 & 355 \\
\hline
\end{tabular}




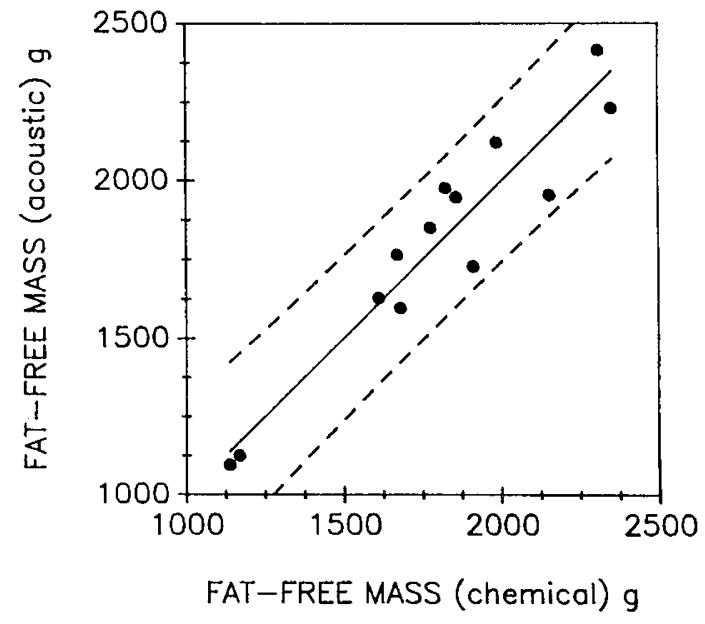

Fig. 4. Relationship between fat-free mass computed from densitometry $(\mathrm{Y})$ and fat-free mass obtained from carcass analysis $(\mathrm{X})$. The solid line represents the data fitted to the equation $\mathrm{Y}=-1 \pm 1.0 \mathrm{X}(r=0.96)$. The SE of estimate of the regression line is $112 \mathrm{~g}$. The dashed line represents the $95 \%$ prediction interval.

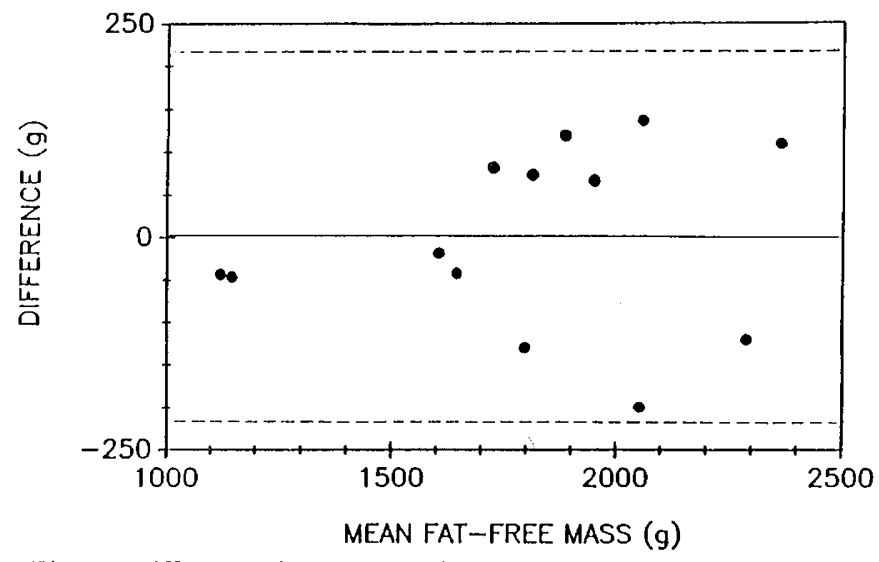

Fig. 5. Differences in FFM obtained by the two methods (acoustic and chemical) are plotted against mean FFM from the two methods. The solid line represents the mean difference and the dashed lines represent the upper and lower limits of agreement (mean difference \pm 2 $\mathrm{SD}$ of the differences) between the two methods.

\section{DISCUSSION}

The acoustic plethysmograph appears to provide a precise and accurate estimate of body volume. Estimates of fat-free mass derived from acoustically obtained body volume values agree closely with those determined by direct chemical analysis of the carcass. Variability in the differences between values derived by the acoustic method and by wet chemistry were greater for fatfree mass than for body volume. The variability of estimates of fat-free mass (2 SD of the difference divided by mean fat-free mass) was $11.9 \%$, a value larger than $3.9 \%$ for body volume measurements. The difference results from the relationship between fat mass and body volume when the densitometric fourcompartment approach is used. As indicated in equation 3, a $1 \%$ error in the measurement of body volume will propagate to a $2.9 \%$ error in the fat-mass estimation. Our results indicate that in a 2000 -g piglet, the acoustic plethysmograph can measure a change in body volume of $75 \mathrm{ml}$ and a change in fat-free mass of $214 \mathrm{~g}$ with $95 \%$ confidence.

Available methods to determine fat-free mass in infants are limited. Fat-free mass or lean body mass can be estimated from total body ${ }^{40} \mathrm{~K}$ determinations $(19,20)$, but facilities for this measurement are not generally available. The estimation of body fat from the solubility of inert gases such as xenon (21) has promise, but this approach requires long periods of confinement before equilibration is achieved. More recently, the perturbation of an electromagnetic field by body electrolytes has been explored and findings have shown an excellent correlation between electrical conductivity measurements and estimates of fat-free mass derived from isotopic water in humans (22) or direct carcass analysis of animals (23). The sensitivity of the method to body geometry, however, must be assessed carefully before its application to rapidly growing infants.

The major uncertainty in the use of acoustic plethysmography is the potential error introduced by the residual volume of air in the lungs and gastrointestinal tract. Total lung capacity and functional residual capacity in a $3-\mathrm{kg}$ newborn infant have been estimated as 5.3 and $2.7 \%$ of body weight, respectively (24). The contribution of air in the gastrointestinal tract to the volume of residual air in infants is not known accurately, but may be significant (25). Furthermore, residual air is not expected to resonate with the free air in the resonating chamber. Thus the volume measured by the acoustic method may be larger than true body volume by at least $2.7 \%$. No mean difference was detected, however, between estimates derived by acoustic plethysmography or direct chemical analysis.

Several possibilities may account for the agreement between the means of the two approaches. Methodological errors may be too large to detect the magnitude of error indicated. Other errors may be introduced by the assumption that the volumes of water, fat, protein, and minerals are additive. In addition, these errors may compensate for each other in a reciprocal manner.

An issue to be resolved with the current prototype acoustic plethysmograph is that measurements of body volume are affected by gross movements of the subject. We believe, however, that because each measurement requires only $1 \mathrm{~min}$, movement artifacts should not complicate measurements in a resting low birth weight infant.

In summary, the capacity of acoustic plethysmography to measure body volume in low birth weight infants has been demonstrated. The usefulness of this measure may be increased when it is combined with the measurements of total body water by tracer methods (e.g. $\left.\mathrm{H}_{2}{ }^{18} \mathrm{O}\right)$, literature values for the body content of minerals $(26,27)$, and density values (for water, minerals, fat, and protein) (1) for estimates of fat-free mass using the densitometric approach.

Acknowledgments. The authors thank D. Barber and J. Kosanovich for technical assistance, E. R. Klein for editorial assistance, and M. E. Lewis and G. Quinones for manuscript preparation.

\section{REFERENCES}

1. Brozek J, Grand F, Anderson JT, Keys A 1963 Densitometric analysis of body composition: revision of some quantitative assumptions. Ann NY Acad Sci 110:113-140

2. Buskirk ER 1961 Underwater weighing and body density: a review of procedure. In: Brozek J, Henshel A (eds) Techniques for Measuring Body Composition. National Research Council, Washington, D.C., pp 90-107

3. Gnaedinger RH, Reineke EP, Pearson AM, Van Huss WD, Wessel JA, Montoye HJ 1963 Determinations of body density by air displacement, helium dilution, and underwater weighing. Ann NY Acad Sci 110:96-108

4. Garn SM, Nolan P Jr 1963 A tank to measure body volume by water displacement (BOVOTA). Ann NY Acad Sci 110:91-95

5. Pearson WR 1963 A photogrammetric technique for the estimation of surface area and volume. Ann NY Acad Sci USA 1 10:109-122

6. Faulkner F 1963 An air displacement method for measuring body volume in babies: a preliminary communication. Ann NY Acad Sci 110:75-79

7. Fomon SJ, Jensen RL, Owen GM 1963 Determination of body volume of infants by a method of helium displacement. Ann NY Acad Sci 1 10:80-90

8. Dell R, Aksoy Y, Kashyap S, Forsythe M, Ramakrishnan R, Zucker C, Heird WC 1987 Relationship between density and body weight in prematurely born infants receiving different diets. In: Ellis KJ, Yasumura S, Morgan WD (eds) In Vivo Body Composition Studies. The Institute of Physical Medicine, London, pp 91-97 
9. Taylor A, Aksoy Y, Scopest JW, duMont G, Taylor BA 1985 Development of an air displacement method for whole body volume measurement of infants. J Biomed Eng 7:9-17

10. Diethelm R, Garrow JS, Stalley SF 1977 An apparatus for measuring the density of obese subjects. J Physiol 267:14

11. Garrow JS, Stalley S, Diethelm R, Pittet PH, Hesp R, Halliday D 1979 A new method for measuring the body density of obese adults. Br J Nutr 42:173183

12. Deskins WG, Winter D, Sheng H-P, Garza C 1985 Use of a resonating cavity to measure body volume. J Acoust Soc Am 77:756-758

13. Deskins WG, Winter D, Sheng H-P, Garza C 1986 An acoustic plethysmograph to measure total infant body volume. J Biomech Eng 107:304-308

14. Chuntananukoon S, Naiborhu A, Setiabudi M, Sheng H-P, Huggins RA 1976 Growth of the pig: patterns of changes in electrolytes, water and protein. Growth 40:99-106

15. Sheng H-P, Garza C, Huggins RA, Smith EO 1982 Comparison of measured and estimated fat-free weight, fat, potassium, and nitrogen of growing guinea pigs. Growth 46:306-321

16. Kraybill HF, Goode ER, Robertson RSB, Sloan HS 1953-54 In vivo measurement of body fat and body water in swine. J Appl Physiol 6:27-32

17. Bland JM, Altman DG 1986 Statistical methods for assessing agreement between two methods of clinical measurement. Lancet 1:307-310

18. Snedecor GW, Cochran WG 1987 Statistical Methods, 6th ed. The lowa State University Press, Ames, IA
19. Novak LP 1973 Total body potassium during the first year of life determined by whole body counting of ${ }^{40} \mathrm{~K}$. J Nucl Med 14:550-557

20. Spady DW, Filipow LJ, Overton TR, Szymanski WA 1986 Measurement of total body potassium in premature infants by means of a whole body counter. J Pediatr Gastroenterol Nutr 5:750-755

21. Mettau JW, Degenhart HJ, Visset HKA, Holland WPS 1977 Measurement of total body fat in newborns and infants by absorption and desorption of nonradioactive xenon. Pediatr Res 11:1097-1101

22. Cochran WJ, Klish WJ, Wong WW, Klein PD 1986 Total body electrical conductivity used to determine body composition in infants. Pediatr Res 20:561-564

23. Fiorotto ML, Cochran WJ, Funk RC, Sheng H-P, Klish WJ 1987 Total body electrical conductivity measurements: effects of body composition and geometry. Am J Physiol 252:R794-R800

24. Comroe JH 1974 Physiology of Respiration, 2nd ed. Yearbook Medical Publisher Inc., Chicago, p 269

25. Calloway DH 1968 Gas in the alimentary canal. In: Code C (ed) Handbook of Physiology, Section 6, Alimentary Canal. Vol V, Bile, Digestion. Ruminant Physiology. American Physiological Society, Washington, D.C., pp 2389_ 2859

26. Fomon SJ, Haschke F, Ziegler EE, Nelson SE 1982 Body composition of reference children from birth to age 10 years. Am J Clin Nutr 35:1169-1175

27. Ziegler EE, O'Donnel AM, Nelson SE, Fomon SJ 1976 Body composition of the reference fetus. Growth 40:329-341 